\title{
Vergílio Ferreira ou a negação do conto
}

Isabel Cristina Rodrigues* 
Os vários géneros e modo literários em que Vergílio Ferreira se exprimiu - o romance, o diário, a poesia lítica, o ensaio e o conto - não têm todos, como bem sabemos, a mesma representatividade no quadro da sua produção literária. Há géneros menores e géneros maiores para Vergílio Ferreira, géneros que correspondem a uma actividade marginal do autor e outros que verdad eiramente sustentam a sua imagem de escritor. Seja como for, todos esses géneros parecem estar sujeitos, ainda que de modo diferente, a um princípio de subsidiariedade ou de transi tividade genológi ca, princípio este que nega ao género literário autonomia de significação e o leva a buscar em géneros de limites exteriores aos seus as virtualidades significativas que Ihe escapam.

Deste modo, ao publicar, em 1976, num só volume e com o título significativo de Contos os textos anteriormente inseridos em A Face Sangrenta e em Apenas Homens, para além de outros contos aparecidos em revistas e em jornais vários, Vergílio Ferreira parece querer assinalar a autonomia desse género que dá nome à colectânea, elaborando assim uma espécie de mecanismo de compensação pelo carácter ambíguo que conferiu ao ensaio e à poesia lírica, ambos parcialmente subordinados à voz omnipresente do romance. Este artifício compensatório, se de facto existiu, redundou numa nova ambigüidade e num novo equívoco, pois a verdade é que, tal como os outros géneros literários, também o conto é em Vergílio Ferreira subsidiário do romance e é dele que verdadeiramente retira substância literária.

A "Nota Introdutória" que o autor escreve para este volume de contos ajuda a esclarecer algumas das questões acima referidas, nomeadamente a do lugar e da função do conto num percurso literário bastante longo, extremamente rico, mas essencialmente romanesco. Confessa Vergílio Ferreira: 
Escrever contos foi-me sempre uma actividade marginal e eles relevam assim um pouco da desocupação e do ludismo. E se um conto (como uma cerâmica ou uma gravura) bem realizado excede em importância um mal realizado romance (ou um quadro a óleo), será sempre um conto, ao que julgo, de uma dimensão menor que a de um romance. Entendo por dimensão a estrutura básica de um género ou forma estética que envolva determinadas possibilidades artísticas e humanas. ${ }^{1}$

Ao conceito de dimensão definido aqui por Vergílio Ferreira subjaz uma clara intencionalidade valorativa que acaba por relegar para segundo plano o género conto, não porque Vergílio Ferreira atribua a este género uma capacidade de realização artística inferior à do romance, mas singelamente porque a sua actividade de contista é de facto marginal ao seu labor de romancista - e a bem da verdade devemos reconhecer que a actividade doutrinária do escritor sempre sucumbiu ao vago propósito de justificar as opções literárias evidenciadas pelos seus textos de criação.

É , portanto, à luz dos romances de Vergílio Ferreira que me parece devermos entender os seus contos; eles ocupam a margem dos romances porque desenham para eles uma espécie de moldura narrativa, porque, em alguns casos, antecipam os próprios romances e tornam inevitável o seu aparecimento ou ainda, noutros casos, porque aparecem mais tarde, sublinhando a necessidade de um qualquer regresso e prolongand o o fascínio de textos que se eternizam. Os contos de Vergílio Ferreira são, em última instância, verdadeiros documentos de trabalho do romancista ${ }^{2}$, uma espécie de ensaios de romance no sentido próprio do termo; são, por fim, textos de carácter pré ou pós-romanesco, textos de feição epigonal que repetem ou antecipam uma situação romanesca, que recuperam personagens ou anunciam criaturas futuras, que reiteram títulos já escritos ou precedem outros por escrever.

A subordinação dos contos de Vergílio Ferreira aos romances do autor é visível desde logo pelos títulos que os primeiros exibem, onde ecoam títulos de alguns romances já publicados ou onde vislumbramos títulos de romances posteriores. Tomemos como exemplo alguns dos textos dos Contos: o primeiro conto da colectânea, escrito em 1949, intitula-se simplesmente "Adeus", o que, para além de evocar inúmeras situações ficcionais que povoam os seus romances (repletos estes de longas despedidas e profundas ausências, de falsas presenças e simulados reencontros), antecipa o título simultaneamente escolhido e abandonado dos

\footnotetext{
FERREIRA, Vergílio. Contos. 5 ed. Lisboa: Bertrand, 1993. p. 7.

Enquanto documentos de trabalho, estes contos volvem-se em perfeitos testemunhos dos rumos seguidos pela sua ficção maior, tal como Conta-Corrente, embora obviamente num outro registo, acompanhou os momentos mais representativos da evolução literária do escritor: os contos O cerco, A Estrela e Uma esplanada sobre o mar, por exemplo, são perfeitos na exemplificação dos momentos de mudança evidenciados pelo seu romance ao longo de mais de cinqüenta anos de vida literária.
} 
romances com o título definitivo de Rápida, a Sombra, Signo Sinal e Para Sempre; estes três romances tiveram efectivamente o título provisório de Adeus, o que é tanto mais curioso quanto se vai tornando evidente que, apesar de o autor não os escolher nunca como títulos definitivos, no romance subsequente voltam a figurar em registo provisório. Veja-se ainda o exemplo do conto "Carta", por sinal o último deste volume, que quase se converte em símbolo da inclinação epistolar de alguns dos seus romances e que, talvez por isso mesmo, estabelece relações de uma certa especularidade com textos como Em Nome da Terra (que teve precisamente o título previsto de Carta), Cartas a Sandra ou ainda com textos como o romance incompleto e inédito Uma Flor, cujo título provisório (Cartas a Diana) voltou a sublinhar a atracção de Vergílio Ferreira por narrativas de carácter epistolar. Por último, não há como evitar a associação do conto "Estrela" ao romance Estrela Polar, adjuvada esta semelhança de títulos pelo facto de o conto ter sido escrito no mesmo ano em que o autor publicou o romance - de resto, o conto em análise, apesar de apresentar uma situação ficcional diferente daquela que é desenvolvida pelo romance em causa, como que insiste na mesma tonalidade metafísica que subjaz ao romance; a procura do absoluto simbolizado pela estrela (polar) que tanto Pedro como Adalberto perseguem e que escapa a um e a outro; a Pedro porque a apropriação clandestina da estrela, que ele rouba do alto da igreja, não poderia dar-Ihe a posse de um bem indevidamente conquistado; a Adalberto, porque a sua peregrinação constante entre Alda e Aida redundou na anulação das duas mulheres e na certeza de que a verdadeira presença do Outro, alternadamente procurada em cada uma das irmãs, se escondia afinal na Estrela Polar, aquela que indica o caminho e o mantém convenientemente longe ${ }^{3}$.

Os títulos de Vergílio Ferreira são, pois, títulos em viagem constante de um texto a outro, mostrando que as palavras de que se compõem os referidos títulos transportam uma carga simbólica tão forte que não podem esgotar-se em aparições singulares e ultrapassam em fascínio o simples exercício de titulação. Por isso, há títulos que se repetem porque há obsessões que se mantêm e, mesmo que seja para excluir depois ${ }^{4}$, os títulos pertencem efectivamente aos textos a que aparecem associados, tal como nos pertencem roupas e objectos que já não usamos mas de que não ousamos desfazer-nos.

3 Poderíamos ainda referir múltiplos exemplos desta errância titular, mesmo entre os romances: o romance Alegria Breve (1965), por exemplo, apresenta como títulos provisórios Cântico Final e A pelo, reenviando ambos para romances já publicados àquela data, respectivamente Cântico Final (1960) e A pelo da Noi te (1963); Em Nome da Terra (1990) apresenta como títulos possíveis Na tua mão (cf. Na tua face (1993) e Plácida, a Noite, aparecendo também este último título com o mesmo estatuto, o de título abandonado, em Para Sempre (1983), ao contrário do estatuto definitivo que veio a adquirir num romance infelizmente abandonado pelo autor em 1983.

4 Como escreveu Vergílio Ferreira (Conta-Corrente 1. 3 ed. Lisboa: Bertrand, 1982. p. 15), um título é a "primeira coisa que se escreve, embora seja a última que se adopta". 
Porém, a negação do conto como género autónomo e auto-suficiente não se reduz a uma mera coincidência ou subordinação de títulos; alguns dos contos presentes neste volume apresentam-se quase como textos preambulares ou epilogais de alguns romances do escritor, tal é a semelhança das histórias que os sustentam. Não há como não recordar no conto "A deus" a melancólica epifania de Para Sempre, onde os momentos de iluminação e milagre são inevitavelmente perturbados por ausências e despedidas; no conto como no romance é a memória recuperadora a responsável pelo reencontro virtual de Paulo e $M$ arta e de Paulo e Sandra. Como diz o Paulo de "Adeus" (mas não o disse também o protagonistas de Para Sempre?):

não Ihe pedi que viesse. Pedi-Ihe só que às dez da noite, e pela última vez, a sua lembrança me esperasse no caminho. Cheguei cedo e sentei-me. Quando soasse a hora, eu queria senti-la ao pé de mim, não bem no seu corpo, não bem nas suas palavras, mas apenas naquele sossego harmonioso que tornava o mundo perfeito. No momento combinado, eu havia de respirar o sonho de quando não sabia que era sonho ${ }^{5}$.

Dir-se-ia, e provavelmente com razão, que neste conto a memória não descobriu ainda o artifício de presentificação que é bem evidente em Para Sempre, bem como em outros romances posteriores, mas de qualquer modo parece-me notável que em 1949, no ano em que Vergílio Ferreira publica Mudança, o papel da memória na recuperação dos momentos de plenitude se revele já de forma tão nítida.

Por sua vez, o regresso da personagem do conto "Carta" à casa da infância e o movimento de revisitação do passado que a acompanha fazem novamente eco na situação vivida por Paulo de Para Sempre ${ }^{6}$, que, à semelhança desta personagem sem nome do conto "Carta", vai ocupando os primeiros instantes desse regresso definitivo com o acto simbólico de abrir as portas e as janelas da casa. Diz a personagem do conto:

Abro as portas da casa deserta, abro as janelas e a varanda. No quintal as ervas crescem com as sombras, as oliveiras têm a cor escura do céu. Em baixo, no chão húmido ao pé da loja, há restos de ferragem enferrujada: um sacho sem cabo, um aro de pipa, um regador ${ }^{7}$.

FERREIRA, Vergílio. “Adeus". In: Contos, ed. cit. p. 9.

A carta que dá nome ao conto é uma carta à pessoa que a personagem procura nesse regresso, tal como aconteceu em Para Sempre e em Cartas a Sandra.

FERREIRA, Vergílio. “Carta”. In: Contos, ed. cit. p. 251-2. 
Recordemos agora as palavras de Paulo, retiradas de Para Sempre, que parecem soar efectivamente como uma versão amplificada das da personagem do conto:

tenho de ir abrir a casa toda, o quarto de Xana é atrás. Mais emperradas as portadas da janela, não vai [...] A portada range, os vidros cheios de pó. E o cheiro a coisas sepultas, apodrecendo na memória. A tarde quieta, é uma tarde de Agosto. A montanha estala à praga do calor. Na parede ao lado, o relógio imóvel. Deve ter parado pela noite quando o tempo se suspende. Se eu the desse corda? Extático o universo. Tenho de ir abrir as janelas. Tenho de ir chamar a Deolinda8.

Estes regressos de $\mathrm{P}$ aulo e da personagem sem nome à casa da infância repetem ainda o movimento supremo e definitivo de Mário em Cânti co Final, que igualmente retorna à casa paterna com a certeza de estar a cumprir o seu derradeiro momento - por isso revela a personagem de "Carta" que o ciclo se fecha com acção de regressar e que, no fundo, tudo está "certo com a vida: o nascer, o partir, o morrer"9.

A profundando ainda um pouco mais esta análise, que pretende descobrir no conto de Vergílio Ferreira os traços genéticos que o associam ao romance e consequentemente o anulam como género autónomo e independente, é perceptível em quase todos os seus contos, como em praticamente todos os seus romances, uma subtil e, todavia, intensa absorção do trágico. Sendo Vergílio Ferreira um escritor que se exprime, quase em exclusivo, através de textos narrativos, não pretendo, contudo, referir-me a quaisquer processos de adaptação da tragédia a textos como os narrativos, mas sim a um outro processo, porventura mais interessante e que pederíamos designar como objectivação do trágico, ou seja, um fenómeno de depuração do género que possibilite, por um lado, a sua libertação da estrutura originária que o enformou (a tragédia grega) e, por outro, a sua virtual insinuação em géneros nem sempre atentos à materialização da sua mundividência. Em última análise é o referido processo ainda visível no nível extra-literário, condicionando os modelos de comportamento do homem comum e determinando a sua percepção do mundo; o texto proverbial acaba por ser o espelho disto mesmo e os ensinamentos que prevê guardam ainda algo da velha sabedoria grega (lembremos exemplos como os dos provérbios "Uma desgraça nunca vem só, "Quem tudo quer tudo perde" ou "Quando mais alto se sobe, maior

Idem. Para Sempre, 2 ed. Lisboa: Bertrand, 1983. P. 37; 135.

Idem, “Carta”, op. cit. p. 251. 
é a queda"). Mais do que uma objectivização do trágico, deparamos com a vulgarização do próprio conceito que, regra geral, tende a designar apenas um qualquer acontecimento fatídico dotado de intensidade negativa, embora normalmente associado aos desígnios e trajectos da vida humana: a morte de uma princesa no auge da juventude e da beleza, um sismo de consequências devastadoras ou a queda de um avião repleto de passageiros. A verdade é que esta objectivização e posterior banalização do conceito tornaram inevitável a percepção do fenómeno em registo de sinédoque: atribuir aos exemplos ainda agora lembrados ( o da princesa, do sismo e do acidente aéreo), a qualificação de eventos trágicos significa apenas associar-Ihes alguns dos atributos previstos pelo conceito (por exemplo, repentino, irremediável, inesperado ou sinistro), quando bem sabemos nós que o trágico não se reduz a um somatório de atributos.

Ora, conhecendo nós o carácter hospitaleiro do romance em relação a géneros e modos de ser tão heterogéneos, é natural que seja ele a instituir-se como nova morada do trágico, sobretudo o romance contemporâneo, que tem sabido sobrepor ao sofrimento do Homem a capacidade de reflexão que também lhe cabe. Dizia K ierkegaard ${ }^{10}$ que na tragédia antiga o sofrimento do $\mathrm{H}$ omem era maior que a sua dor e que na moderna era a dor maior que o sofrimento, uma vez que este último implica uma maior dose de objectividade que a dor e que esta supõe já uma capacidade de reflexão sobre o próprio acto de sofrer; é isto uma sólida verdade igualmente para o romance contemporâneo e, em concreto, para o romance de Vergílio Ferreira, bem como para alguns dos seus contos, em função do estatuto de subsidiariedade que o autor Ihes atribui.

A expressão trágica da obra de Vergílio Ferreira envolve, para além da sua mais conhecida dimensão metafísica, também uma dimensão social da questão que, pelo menos nesta colectânea de contos, assume a forma da parábola; contos como "O Morto", "Linha Quebrada" e sobretudo "O J ogo de Deus" são textos atravessados por uma visão ironicamente amarga (e todavia lúcida) da sociedade contemporânea, cujo saldo é a denúncia do perigo das ortodoxias ferozes e das hegemonias ideológicas. Em "O J ogo de Deus", e destaco-o dos outros dois pela sua exemplaridade, deparamos com uma parábola muito curiosa da relação dos homens com o poder: este conto situa-nos em face de um condenado à morte, que o foi porque duvidou da divindade do seu líder, um antigo companheiro seu dos tempos de juventude. A descrença do narrador na divindade do seu antigo companheiro Artur advém do facto de ele estar demasiado próximo, quando de um Deus esperamos superioridade e distância. Por isso confessa o condenado: 
U m vazio enorme, uma descrença absoluta na divindade de Artur quebrava-me o entusiasmo. Se Artur ao menos fosse outro, um homem desconhecido, subitamente revelado em maravilha e poder, eu arriaria talvez por dentro como arriara por fora. M as conhecia Artur desde a instrução primária, emprestara-Ihe dinheiro nos fins de mês, sabia, sobretudo, desde há muito, que ele tinha uma úlcera no duodeno ${ }^{11}$.

Porém, a maior parte dos textos destes Contos textualiza prioritariamente a dimensão metafísica do trágico e isto porque, tal como em toda a obra vergiliana, é neles muito clara a presença de alguns factores que favorecem a experiência trágica. Diz-nos G erd B ornheim ${ }^{12}$ que deve haver algo no Homem que possibilite a vivência trágica, uma vez que o trágico não é em si próprio um valor, só se manifestanto quando adere a determinados valores como, por exemplo, a ideia de finitude, de contingência ou de limite. Estes valores podem ou não ser vividos de modo trágico (em Vergílio Ferreira são-no sem sombra de dúvida), o que em parte explica a existência de algumas épocas especialmente atentas à manifestação do trágico e de outras que permanecem cegas à sua representatividade. D este modo, quando Sartre se refere àquilo que designa por separação ontológica, reenviando este conceito para a impossibilidade ontológica do Homem aceder ao objecto das suas buscas e interrogações, está como que a descrever uma situação central a toda a problemática vergiliana, a que os contos também não são alheios.

O emparedamento do Homem vergiliano, face ao limite que constitui a sua condição de ser mortal, torna previsível a reiteração em registo ficcional daquilo a que o autor chamou precisamente a situação-limite e que, como acontece em alguns dos contos, pode coincidir com o momento supremo e decisivo da vida, ou seja, a morte. Três das personagens destes contos ( o condenado de "O J ogo de Deus", o "preso", tal como é designado o protagonista de "Saturno", e a personagem I nocêncio do conto "O Espirro"), apesar de protagonizarem histórias ligeiramente diferentes, possuem um destino comum, visto que os três estão condenados à morte e vivem, no momento em que a narração os surpreendeu, o dia da execução das respectivas penas. Vergílio Ferreira coloca os três no momento da verdade absoluta que favorece a percepção trágica da vida e, desse modo, parece querer elevá-los ao estatuto de heróis trágicos; como diz a personagem de um outro conto ( "Uma esplanada sobre o mar") ,a morte "é a única verdade perfeita"13 e pode, por isso, confundir-se com o momento de suprema revelação ou de pura

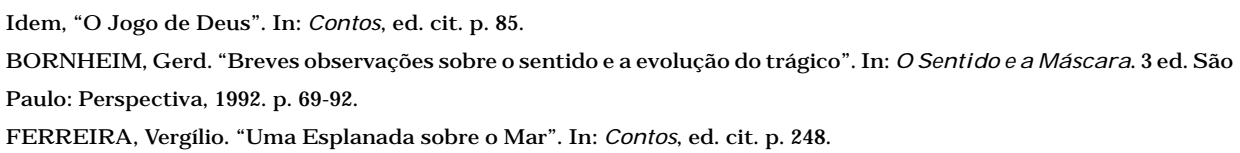


materialização do absoluto em espíritos não destituídos de sensibilidade para o trágico. É o que ocorre com a personagem Inocêncio do conto "O Espirro", no momento de subir os degraus da forca:

O padre teimava em dizer ainda coisas em voz baixa a Inocêncio, mas ele não prestava atenção. Olhava era a forca, ou não bem a forca, mas, mais alto do que isso, o céu azul. Porque estava um dia esplendoroso [...] Um galo cantou longe e Inocêncio ouviu-o porque havia muito silêncio. Começou, então, a subir os degraus da forca. Olhou ainda o céu, que estava realmente bonito. [...] I nocêncio ouviu ainda outra vez o galo lá longe. Cantava para a manhã que raiava. E era belo ouvi-lo com o seu sinal de triunfo ${ }^{14}$.

Alguns dos atributos evidenciados pelos heróis trágicos (como a dicotomia ousadia/submissão ao castigo) estão, por sua vez, presentes em algumas personagens dos contos de Vergílio Ferreira, como em Pedro do conto "A E strela", nos condenados à morte dos três contos de há pouco ou ainda no jovem de "Uma Esplanada sobre o mar". Pedro, o usurpador da estrela que morava no céu, por cima da igreja da sua aldeia, parece resultar do cruzamento simbólico das figuras mitológicas de Prometeu e Ícaro ${ }^{15}$, uma vez que, roubando a estrela, apropriou-se do fogo do céu, e a punição pela sua ousadia foi cair como Í caro; a morte de Pedro aparece como um castigo supremo reclamado por uma ousadia também suprema, ousadia esta que se volve em metáfora da hybris da grande maioria das personagens vergilianas, sempre em busca da eternidade, apesar de saberem que o B em é por natureza precário e que de tudo terão de abdicar um dia, cedo ou tarde - da juventude, do convívio com a mulher que amam e por último também da vida. Contudo, a verdadeira sabedoria trágica é a da reconciliação do Homem com o seu destino, é, em suma, a sabedoria da resignação - Pedro devolveu a estrela que roubara, vergando-se ao castigo estipulado pelo pai e aprovado por toda a aldeia; os condenados à morte caminham resignados para o cadafalso e mesmo o rapaz de "Uma E splanada sobre o Mar" aceita a sua condenação como uma ode à vida:

O médico foi claro. Havia um relógio na secretária e olhei as horas. Eram cinco precisas. Estava calmo e reparei. Tenho dois ou três meses no máximo. $\mathrm{O}$ tempo contado dia a dia. E é extraordinário como tudo agora me parece diferente. Mais belo talvez. Creio que vou viver agora mais intensamente. Dia a Dia. E três meses no máximo16.

14 Idem, “O Espirro". In: Contos, ed. cit. p. 224.

15 Cf. GODINHO, H. “Para a determinação do mitoestilo do conto 'A Estrela', de Vergílio Ferreira”. I n: O Mito e o Estilo. Lisboa: Presença, 1982. p. 53-93.

16 FERREIRA, Vergílio. “Uma Esplanada sobre o mar". In: Contos, ed. cit. p. 249. 
Há neste conto uma nítida disjunção entre a experiência trágica das personagens e a plenitude solar da paisagem marítima que invade a esplanada onde o jovem revela à rapariga a sua iminente condenação; é esta também uma imagem recorrente na ficção de Vergílio Ferreira, a da esplanada sobre o mar, metáfora a todos os títulos notável daquela capacidade do sujeito para perspectivar a partir do trágico da sua condição o absoluto que o destino insiste em recusar-Ihe. Também no romance Em Nome da Terra encontramos J oão e M ónica numa esplanada invadida pela luz solar e que assinala por antítese a degradação que se havia já instalado no quotidiano das personagens e é por isso que J oão nota:

Havia um contraste muito forte entre a tua imagem e o azul do rio bastante largo para parecer um mar... Lembro a luz forte no ar e tu composta à mesa mas com um desarranjo no teu modo de estar e que já não eras tu. ${ }^{17}$

Por tudo isto lembrou Vergílio Ferreira, na sua subtil consciência do trágico, que "a vida não se excede a si própria e tudo o que está para além disso é uma ridícula galinha de barro"18 , numa clara alusão a um dos contos desta colectânea, precisamente intitulado "A Galinha", onde o autor igualmente revela a sua visão trágica da vida:

O homo homini lupus era-me de trágica evidência nas contendas absurdas que presenciara na infância. Mas só tarde aprendi que a aldeia era o mundo ${ }^{19}$.

\footnotetext{
Idem, Em Nome da Terra. 2 ed. Lisboa: Bertrand, p. 87-8.

Idem, Espaço do Invisível. 5 ed. Lisboa: Bertrand, 1998. p. 18

Idem, ibidem, p. 15.
} 